\title{
Juan Carlos Cabañas García, El derecho a la igualdad en la aplicación judicial de la ley, Aranzadi-Thomson Reuters, Pamplona, 2010, 278 pp.
}

I. Existen, hasta el momento, salvo error u omisión, solamente dos monografías más sobre el tema, por cierto excelentes, una de un filósofo del Derecho (Andres Ollero Tassara: Igualdad en la aplicación de la ley y precedente judicial, CEPC, Madrid, 2005) y otra de dos laboralistas (Rodríguez-Piñero, Miguel y Fernández López, María Fernanda: Igualdad y discriminación, Tecnos, Madrid, 1986).

Por esta razón, creo que el libro publicado por el profesor Cabañas, insigne procesalista y veterano Letrado del Tribunal Constitucional, era necesario. El primer procesalista que aborda el tema en una monografía de forma sistemática y acabada, es por tanto, el profesor Cabañas. Debe subrayarse que lo hace de forma sistemática y acabada. En efecto, dicen que Spinoza intentó demostrar la ética como si fuera geometría. Personalmente, desconfío de la traslación al Derecho y a las Humanidades de los métodos de otras ciencias, pero reconozco que el edificio que construye en este libro nuestro autor evoca el rigor, el carácter omnicomprensivo y la belleza de la geometría.

Pero es que además, hay que subrayar que este es un tema en el que precisamente deben colaborar los procesalistas, pues son en gran medida razones de Derecho procesal las que han conducido a que la igualdad en la aplicación de la ley juegue el papel que juega en la actualidad entre nosotros.

II. El libro está estructurado en tres capítulos. El primero se dedica a la delimitación del contenido esencial del derecho. El segundo se dedica a los elementos del juicio de igualdad y su control. El tercero, a los mecanismos para la protección del derecho. Siendo, como es, muy sugerente, son muchos los puntos que podrían tratarse. Sin embargo, en esta recensión, me voy a referir aquellos que más me han llamado la atención desde el punto de vista del Derecho constitucional. Así, del capítulo primero, me voy a detener en tres puntos: las propuestas formuladas sobre el contenido esencial del derecho; el debate sobre el enclave formal del derecho; y la distinción entre igualdad ante la ley e igualdad en la aplicación de la ley.

1. Comienza el profesor Cabañas explicando que el derecho a la igualdad en la aplicación judicial de la ley es un derecho fundamental que ha creado nuestro Tribunal Constitucional a partir del artículo $14 \mathrm{CE}$ y que en ese proceso creador ha conocido varias formulaciones.

Por una parte, existe la versión mayoritaria, la que aparece en más sentencias, la predominante, la más conocida, que es la que lo concibe como derecho a la obtención de una tutela judicial acorde con criterios de decisión ya asumidos antes por el mismo órgano judicial. El recurrente en amparo que invoque este derecho habrá de aportar las sentencias anteriores del mismo órgano judicial con las que realizar la comparación o sentencias de contraste, que deben referirse a sujetos distintos (alteridad), deben proceder de idéntico 
órgano judicial (hasta el nivel de Sección) y además, debe faltar en la sentencia impugnada cualquier motivación que justifique cambio de criterio.

Pero junto a esta versión del derecho a la igualdad en la aplicación judicial de la ley, nuestro Tribunal ha formulado otras, principalmente otra, diseñada en la STC 144/1988 y concordantes, conforme a la cual el contenido de tal derecho sería la prohibición de una tutela judicial basada en alguna de las desigualdades expresamente proscritas por la Constitución en su artículo 14. El autor señala que esa línea nunca ha sido cerrada y además trae a colación trabajos de autores que auspician su potenciación, en particular los de Mercader Uguina, "El imposible derecho a la igualdad en la aplicación judicial de la ley en la doctrina constitucional", en El Proceso laboral. Estudios en Homenaje al profesor Luis Enrique de la Villa Gil (AAVV); editorial Lex Nova, Valladolid, 2001, página 634, y Rubio Llorente, "La igualdad en la aplicación de la ley", en el Anuario de la Facultad de Derecho de la Universidad Autónoma de Madrid, número 1, La vinculación del juez a la ley, Madrid, 1997 página 156.

2. Es interesante aludir, en segundo lugar, a un punto en que el autor discrepa de la opción seguida en la mayoría de las sentencias del Tribunal. Me refiero a la cuestión del enclave del derecho a la igualdad en la aplicación de la ley tal y como lo configura la mayoría de las sentencias del Tribunal. Hay que subrayar esta última condición, pues el autor reconoce que si el contenido del derecho fuera el de la STC se 144/1988, su ubicación sería el art. 14 CE.

Hay que señalar ante todo es que la ubicación en el artículo 14 o en el 24, ambos CE, no es sólo una cuestión teórica, sino que condiciona la vía judicial previa al amparo ante el Tribunal Constitucional. En efecto, en función de que se considere infracción sustantiva o procesal, su control en sede de recursos extraordinarios puede ser distinto según el orden jurisdiccional donde nos hallemos (así, casación o bien recurso extraordinario por infracción procesal en el ámbito civil).

Pues bien, el autor, como en todos los puntos que aborda lo largo del libro, comienza sistematizando las diversas respuestas que ha dado el Tribunal a la cuestión: en la mayoría de los casos encuadra el Tribunal este derecho en el arte $14 \mathrm{CE}$; si falta la alteridad, incardina el caso en el art. 24.1 CE; y existen casos en que, sin explicación del por qué, el Tribunal considera que cabe incardinar el derecho en cuestión en cualquiera de los dos preceptos que se plantean como posibles: el 14 y el 24.1, ambos CE.

En este punto nuestro autor, escrupulosamente respetuoso a lo largo de todo el libro con el Tribunal, se permite manifestar su discrepancia: tal y como lo interpreta la mayoría de los sentencias del Tribunal Constitucional, sostiene Cabañas, el derecho a la igualdad en la aplicación de la ley, es una variante patológica del correcto enjuiciamiento judicial, que por tanto encuentra su encaje más apropiado en el arte $24.1 \mathrm{CE}$.

3. La afirmación de este enclave constitucional para el derecho en la aplicación judicial de la ley hace necesaria la distinción entre este derecho y el 
derecho a la igualdad ante la ley del arte $14 \mathrm{CE}$, así como del valor de la igualdad del art. 9.2 CE, lo que el autor hace con precisión a continuación en las páginas 51 y siguientes.

Señala nuestro autor que el derecho a la igualdad en la aplicación judicial de la ley, tal como lo formulan la mayoría de las sentencias del Tribunal, es distinto de la igualdad ante la ley (que identifica con la igualdad en la ley, aún sabedor de que la cuestión no es pacífica) y que el propio Tribunal en muchas sentencias los distingue haciendo alusión a que esta última se desarrolla en el ámbito material, mientras que la primera se desarrolla en el ámbito formal.

Continúa su análisis señalando e ilustrando que la confusión entre ambas sí se produce en la jurisdicción ordinaria.

4. Dentro de las cuestiones tratadas en el capítulo segundo vamos a detenernos en tres. el problema de la exigencia de que sea la misma Sección la que el dictado las sentencias de contraste; el juicio de contraste, es decir la similitud de casos y disparidad de soluciones jurídicas y las modalidades aceptadas del precedente.

Nuestro autor no deja flecos.

Así por ejemplo, afronta el problema que plantea la exigencia de la doctrina del Tribunal (con la excepción de la relativa de la STC 339/2006, de 11 diciembre, FJ 5, al que se refiere) conforme a la cual para estimar la vulneración del derecho en la aplicación judicial de la ley es necesario que las sentencias de contraste procedan incluso de la misma Sección (páginas 78 y ss).

Y aquí hace un alarde de su formación como jurista y procesalista pues no critica el fenómeno porque de esta manera el derecho quede reducido a muy poco, sino que explica y puntualiza que tal exigencia descansa en un error de apreciación del significado de la autonomía de las secciones, que es meramente orgánica, pero que no implica especialización: la diversificación de sus competencias materiales queda confiada a los acuerdos de sus Salas de gobierno acerca del reparto de asuntos, los cuales se guían generalmente por criterios objetivos pero coyunturales de mera necesidad del servicio, volumen pendiente y repetición de causas; en definitiva, criterios cambiantes y no estructurales. Además, la diversificación ab initio no garantiza muchas veces nada, pues por mandato gubernativo pueden existir dos o más secciones dedicadas a temas comunes.

En suma, la especialización sólo adquiere relevancia material cuando se distingue entre Salas.

5. Otro punto a destacar en el estudio es el análisis del juicio de contraste: la similitud de casos y disparidades soluciones jurídicas (páginas 87 y ss.). ¿Cómo determinar el grado de semejanza necesaria entre supuestos controvertidos para fundar el debido tertium comparationis?

El autor nos dice que nuestro Tribunal Constitucional habla de identidad "sustancial", en caso de línea jurisprudencial, mientras que en caso del precedente aislado pero cercano en el tiempo parece preferir la expresión "antecedente inmediato en el tiempo y exactamente igual desde la perspectiva 
jurídica con la que se enjuició". Pero de estas diferentes expresiones no hay que extraer consecuencias jurídicas tal y como propone nuestro autor.

Aunque el Tribunal no defina qué es lo "sustancial" o lo "exactamente igual", Cabañas nos ofrece un elenco de datos diferenciadores que no podemos exponer aquí, que, fundándose en la jurisprudencia del Tribunal impiden la concurrencia de igualdad sustancial o de identidad:

6. Completamente exhaustivo y comprometido es el análisis que se ofrece en la monografía de otra difícil cuestión en la configuración de este derecho fundamental: la de las modalidades aceptadas del precedente (pp. 106 y ss.). El análisis es exhaustivo porque, hasta donde se nos alcanza, no se echa de menos ninguna resolución relevante en el tema; y es comprometido por ofrecer un criterio para interpretar los titubeos del Tribunal en el tema.

Comienza el libro la exposición señalando que el criterio consolidado del Tribunal es la exigencia de una línea interpretativa del órgano judicial contraria a la resolución impugnada. Es decir, que no bastaría para acreditar la vulneración de este derecho una sola sentencia distinta de contraste. Continúa trayendo a colación las sentencias en que el Tribunal ha considerado que se vulnera el derecho a la tutela judicial en la aplicación de la ley también cuando hay un solo precedente contrario pero cercano en el tiempo; incluye, por supuesto, los casos en que el Tribunal ha otorgado amparo por la existencia de precedente cercano en el tiempo y aislado pero con base en el arte 24.1 $\mathrm{CE}$, no en el $14 \mathrm{CE}$; y finalmente incluye casos en que se percibe un relativo "arrepentimiento" del Tribunal por haber aceptado precedentes aislados y cercanos como sentencias de contraste válidas para otorgar amparo.

Pero el Profesor Cabañas no se limita a registrar titubeos en el comportamiento del Tribunal, sino que ofrecer su criterio interpretativo fundado de este laberinto de resoluciones: "todavía más recientemente, dice, el Tribunal vuelve a aceptar la tesis del precedente aislado no sólo a los efectos de recordar su doctrina sino de estimar el amparo con base en él (STC 31/2008, de 25 febrero, FJ 3); por lo que aquellas abjuración es a la figura del precedente aislado han de tomarse todavía como excepcionales y no indicativas de un cambio de la jurisprudencia" (página 118).

7. No nos queda espacio para comentar todos los aspectos que querríamos. Decíamos que el trabajo no deja flecos que se nos alcancen. Buena prueba de ello es el análisis que se hace de la sentencia estimatoria del amparo (pp. 180 y ss.), único punto del capítulo tercero al que vamos a referirnos porque es el que más directamente nos concierne, sin perjuicio de advertir el ímprobo y sobresaliente esfuerzo realizado en la monografía para el examen pormenorizado y sistemático que se lleva a cabo de la jurisprudencia de las distintas Salas del Tribunal Supremo en relación con la correcta $-\mathrm{y}$ a veces también imprecisa- aplicación de este derecho fundamental.

Comienza, en lo que vamos a recalcar, señalando el autor que la sentencia de amparo no debe quedar constreñida en función de las pretensiones deducidas en la demanda y que las medidas que se revelan como imprescindibles 
y naturales para la reparación del derecho vulnerado deben ser impuestas por el Tribunal Constitucional al margen de la destreza del recurrente.

Continúa diciendo que, en el derecho que nos ocupa, la sentencia estimatoria habrá de incluir los tres tipos de pronunciamientos que prevé el art. 55 LOTC: declaración de nulidad de la resolución o resoluciones vulneradoras; reconocimiento del derecho fundamental vulnerado y medidas para el restablecimiento del recurrente en la integridad de su derecho.

A continuación pasa a justificar por qué, en su criterio, la sentencia no debe limitarse a acordar la retroacción de actuaciones.

Para ello, previamente examina las fórmulas empleadas por nuestro Tribunal Constitucional para la reparación efectiva del derecho, que clasifica de manera acabada.

No acaba aquí el concienzudo análisis de la práctica judicial. El autor ha seguido la pista a aquellos asuntos en los que la respuesta de la jurisdicción ordinaria en vía ejecutoria es posible por su publicidad. En este sentido, analiza qué ha hecho el Tribunal Supremo en los casos del fallo clásico del Tribunal Constitucional que no predetermina la solución a adoptar y constata que el Tribunal Supremo unas veces ha aceptado sin más que había que volver al criterio precedente, en alguna otra ocasión ha mantenido el criterio de la resolución recurrida, si bien proporcionando la correspondiente motivación, otras ha defendido tenuemente el criterio de la recurrida pero resuelve que en ese caso es mejor volver al criterio de la precedente, otras ha dictado una nueva sentencia con el mismo fallo pero con una nueva forma de enjuiciar el asunto.

Como colofón de este notable esfuerzo, el autor ofrece el que debe ser el criterio correcto: la sentencia que otorgue el amparo debe imponer al órgano judicial que dicte una resolución acorde con su precedente, y ello por las siguientes razones:

- En caso contrario, la igualdad judicial se diluye y se vacía de contenido, pasando a transformarse en una expresión más de falta o defecto de motivación, lo que no es.

- Con ello el Tribunal Constitucional no se pronuncia sobre la legalidad del criterio precedente cuya aplicación se ordena, con lo que no invade competencias de la jurisdicción ordinaria.

Cierra su acabada argumentación el autor señalando que la única excepción que cabe conceder a este régimen de imposición directa del precedente no aplicado sería la de los casos en que el Tribunal Constitucional declare expresamente cometida la vulneración por una inadvertencia del órgano judicial sobre la preexistencia de dicho precedente.

III. El libro está escrito desde la posición de Letrado, y acaso por ello es escrupulosamente respetuoso con la jurisprudencia del Tribunal Constitucional, que expone de manera exhaustiva. Pero también ofrece un estudio acabado de la doctrina científica. 
La lectura del libro es un placer intelectual y además un ejercicio saludable y formativo. La precisión terminológica es magnífica. La soltura con que en una breve cita o inciso resuelve problemas o fija criterio en cuestiones de primera magnitud resulta admirable. El libro muestra que el autor es capaz de hacer consideraciones de Derecho constitucional y descender a las más concretas cuestiones de legalidad ordinaria. Casi diría que muestra que para hacer cualquiera de esas dos cosas bien, hay que hacer también la otra.

Es un libro cuya lectura, estudio o consulta es altamente recomendable para el estudiante, para el abogado, para el profesor.

Diría que con este libro queda despejado, quizás, el camino para la regulación legal de este derecho de creación del Tribunal Constitucional.

Pedro J. Tenorio Sánchez

UNED 